\title{
Surgical results of pars plana vitrectomy combined with pars plana lensectomy with anterior capsule preservation, endophotocoagulation, and silicon oil tamponade for neovascular glaucoma
}

\author{
This article was published in the following Dove Press journal: \\ Clinical Ophthalmology \\ 15 December 2011 \\ Number of times this article has been viewed
}

\section{Nozomi Kinoshita \\ Ayumi Ota \\ Fumihiko Toyoda \\ Hiroko Yamagami \\ Akihiro Kakehashi}

Department of Ophthalmology, Saitama Medical Center, Jichi Medical

University, Saitama, Japan
Correspondence: Akihiro Kakehashi, Department of Ophthalmology, Saitama Medical Center, Jichi Medical University, I-847 Amanuma-cho, Omiya-ku,

Saitama, 330-8503, Japan

$\mathrm{Tel}+8 \mathrm{I} 486472 \mathrm{III}$

Fax+8I 486485188

Email kakeaki@omiya.jichi.ac.jp
Purpose: To report on pars plana vitrectomy (PPV) combined with pars plana lensectomy (PPL) with a preserved anterior capsule, panretinal endophotocoagulation (EPC) throughout the pars plana, and silicon oil (SO) tamponade (PPV + PPL + EPC + SO tamponade) for neovascular glaucoma (NVG).

Methods: Thirteen eyes with NVG were treated. Ten eyes also underwent SO removal and intraocular lens (IOL) implantation (SO removal + IOL). Intraocular pressure (IOP), number of medications, and visual acuity were evaluated at the first visit, immediately before and 3 months after the procedure, 3 months after SO removal + IOL, and 1 year after the procedure.

Results: At the first visit, immediately before and 3 months after the procedure, 3 months after SO removal + IOL, and 1 year after the procedure, the IOPs were $29 \pm 19,23 \pm 12,13 \pm 5$, $17 \pm 10$, and $17 \pm 6 \mathrm{mmHg}$; numbers of medications, $0.7 \pm 1.4,2.1 \pm 2.0,0.6 \pm 0.7,1.2 \pm 1.2$, and 1.6 \pm 1.6 ; and best-corrected visual acuities converted to logarithm of the minimum angle of resolution (BCVA logMAR), 0.96 $\pm 0.96,1.27 \pm 0.80,1.67 \pm 0.91,1.37 \pm 0.89$, and $1.90 \pm 1.44$, respectively. No severe hypotony or phthisis bulbi developed within 1 year after the procedure. The success rates (IOP $\leq 21 \mathrm{mmHg}$ and sustained light perception) were $92.3 \%$ after 3 months and $69.2 \%$ after 1 year.

Conclusion: PPV + PPL + EPC + SO tamponade might have prevented acute increases of vascular endothelial growth factor and inflammatory cytokine production postoperatively and resulted in good vision in patients with NVG.

Keywords: pars plana vitrectomy, pars plana lensectomy, panretinal endophotocoagulation, silicon oil, neovascular glaucoma

\section{Introduction}

Neovascular glaucoma (NVG) develops in cases with extensive ischemic retinal changes, such as proliferative diabetic retinopathy (PDR) and central retinal vein occlusion (CRVO). Vascular endothelial growth factor (VEGF) and inflammatory cytokines from the ischemic retina are thought to cause NVG. ${ }^{1-3}$ VEGF and inflammatory cytokines from the ischemic retina migrate to the anterior segment and stimulate the neovascularization in the iris and the angle. When neovascular fibrous tissues occupy the trabecular meshwork, aqueous outflow is disturbed and NVG develops eventually.

NVG is generally difficult to treat. Prophylactic panretinal photocoagulation (PRP) prevents development of $\mathrm{NVG}^{4-6}$ and can be effective for early-stage NVG. ${ }^{7,8}$ Application of PRP induces regression of neovascularization in the angle, and aqueous outflow can be 
initiated in open-angle NVG. However, in angle-closure NVG, PRP cannot restore aqueous outflow, ${ }^{9-11}$ and trabeculectomy or cyclo-cryo/photocoagulation of the ciliary body is the final treatment option. ${ }^{12-14}$ However, the surgical results are usually dismal. ${ }^{14-17}$ Obtaining regression of neovascularization during the open-angle stage of the disease is the most important strategy for treating NVG.

Although pars plana vitrectomy (PPV) and additional retinal photocoagulation are the next options for treating NVG, the surgical results are unfavorable. Aphakia especially is a risk factor for development of rubeosis. ${ }^{18}$ Patients who are pseudophakic are thought to have a better chance of not developing rubeosis postoperatively than phakic patients. ${ }^{19}$ Considering this, we previously performed PPV + phacoemulsification + intraocular lens (IOL) impantation + panretinal endophotocoagulation (EPC) to treat NVG. However, we experienced some advanced cases that developed extensive fibrin and worsening of rubeosis despite this procedure. Incomplete vitrectomy and incomplete retinal photocoagulation to the peripheral pars plana seem to cause extensive fibrin and worsening rubeosis. Therefore, we performed PPV combined with pars plana lensectomy (PPL) with preservation of the anterior capsule, EPC throughout the pars plana, and silicon oil (SO) tamponade $(\mathrm{PPV}+\mathrm{PPL}+\mathrm{EPC}+$ SO tamponade) to treat NVG. The aim of the current study was to evaluate the results of this new surgical procedure, $\mathrm{PPV}+\mathrm{PPL}+\mathrm{EPC}+\mathrm{SO}$ tamponade, for open-angle NVG.

\section{Patients and methods}

Thirteen eyes of eleven cases with NVG were included from July 2004 to January 2007 and underwent PPV + PPL + EPC + SO tamponade. All eyes had undergone PRP previously and were diagnosed with open-angle NVG. Twelve eyes had a history of PDR and one eye had a history of CRVO; the mean patient age (mean \pm standard deviation [SD]) was $57.9 \pm 10.5$ years. The male:female ratio was 9:2. Ten eyes of nine cases also underwent SO removal and IOL implantation (SO removal + IOL); the mean patient age was $59.3 \pm 10.6$ years. The male:female ratio was 7:2. The interval between $\mathrm{SO}$ tamponade and removal (mean \pm SD) was $205 \pm 91$ days.

We performed PPV using a three-port technique in all patients. We performed PPL extraction in twelve phakic eyes using the Fragmatome (Alcon, Fort Worth, TX) and preserved the anterior lens capsule. The IOL was left in place in one pseudophakic eye. During PPV, posterior hyaloid separation was induced by suction using the vitreous cutter over the optic nerve head in a case without a posterior vitreous detachment. Fibrovascular membranes were removed using the total en-bloc excision technique. ${ }^{20}$ After PPV, EPC was performed throughout the pars plana, and the vitreous cavity was filled with SO.

We evaluated the intraocular pressure (IOP), the number of both antihypertensive eye drops and oral medicines used, and the visual acuity (VA) using a Snellen chart at the time of the first visit, immediately before and 3 months after $\mathrm{PPV}+\mathrm{PPL}+\mathrm{EPC}+\mathrm{SO}$ tamponade, another 3 months after $\mathrm{SO}$ removal $+\mathrm{IOL}$, and 1 year after $\mathrm{PPV}+\mathrm{PPL}+\mathrm{EPC}+\mathrm{SO}$ tamponade. The best-corrected decimal visual acuity was converted to the logarithm of the minimum angle of resolution (BCVA $\log \mathrm{MAR}$ ). Mermoud et $\mathrm{al}^{21}$ defined therapeutic success as an IOP $\leq 21 \mathrm{mmHg}$ and the presence of sustained light perception vision. Using these criteria, we calculated the success rates 3 months and 1 year after $\mathrm{PPV}+\mathrm{PPL}+\mathrm{EPC}+\mathrm{SO}$ tamponade.

The Wilcoxon signed-rank test was used for statistical analysis in this study. The values are expressed as the mean \pm SD. $P<0.05$ was considered statistically significant.

\section{Results}

At the first visit, immediately before, and 3 months after $\mathrm{PPV}+\mathrm{PPL}+\mathrm{EPC}+\mathrm{SO}$ tamponade, another 3 months after $\mathrm{SO}$ removal $+\mathrm{IOL}$, and 1 year after $\mathrm{PPV}+\mathrm{PPL}+\mathrm{EPC}+\mathrm{SO}$ tamponade, the mean IOPs (mean $\pm \mathrm{SD}$ ) were $29 \pm 19$, $23 \pm 12,13 \pm 5,17 \pm 10$, and $17 \pm 6 \mathrm{mmHg}$ (Figure 1); the numbers of medications (mean $\pm \mathrm{SD}$ ) were $0.7 \pm 1.4$, $2.1 \pm 2.0,0.6 \pm 0.7,1.2 \pm 1.2$, and $1.6 \pm 1.6$ (Figure 2); and the BCVA $\log$ MAR (mean \pm SD) were $0.96 \pm 0.96$, $1.27 \pm 0.80,1.67 \pm 0.91,1.37 \pm 0.89$, and $1.90 \pm 1.44$, respectively. The IOP and the numbers of both antihypertensive eye drops and oral medications used for 3 months after $\mathrm{PPV}+\mathrm{PPL}+\mathrm{EPC}+\mathrm{SO}$ tamponade decreased significantly compared with immediately before $\mathrm{PPV}+\mathrm{PPL}+\mathrm{EPC}+\mathrm{SO}$ tamponade $(P<0.05)$. However, the IOP and the numbers of both antihypertensive eye drops and oral medications used for another 3 months after SO removal + IOL and 1 year after PPV + PPL + EPC + SO tamponade did not decrease significantly compared with immediately before $\mathrm{PPV}+\mathrm{PPL}+\mathrm{EPC}+\mathrm{SO}$ tamponade.

An IOP of $21 \mathrm{mmHg}$ or lower was maintained in twelve of 13 eyes (92.3\%) 3 months after PPV + PPL + EPC + SO tamponade, and an IOP of $21 \mathrm{mmHg}$ or lower was maintained in eight of ten eyes (80\%) 3 months after SO removal + IOL with or without medications. An IOP of $21 \mathrm{mmHg}$ or lower was maintained in eleven of 13 eyes $(84.6 \%) 1$ year after PPV + PPL $+\mathrm{EPC}+\mathrm{SO}$ tamponade with or without 


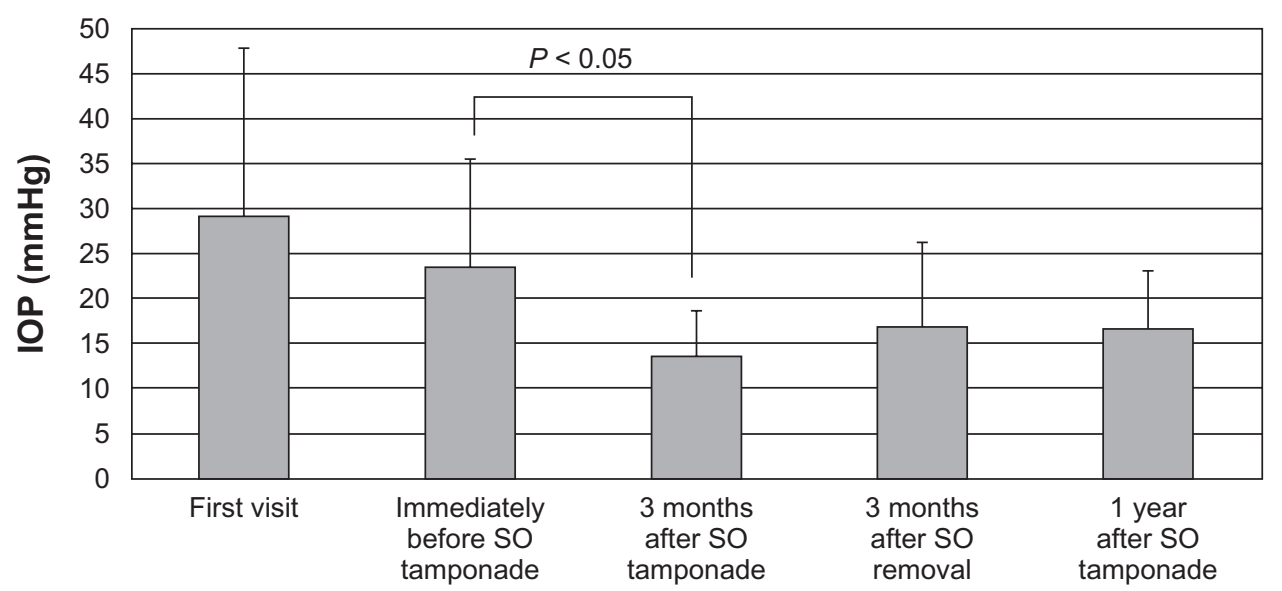

Figure I The time course of IOP changes. At the first visit, immediately before and 3 months after PPV + PPL + EPC + SO tamponade, 3 months after SO removal + IOL, and I year after PPV + PPL + EPC + SO tamponade, the IOPs (mean \pm SD) were $29 \pm 19,23 \pm 12,13 \pm 5,17 \pm 10$, and $17 \pm 6 \mathrm{mmHg}$.

Abbreviations: $\mathrm{mmHG}$, millimeters of mercury; IOP, intraocular pressure; SO, silicon oil; PPV, pars plana vitrectomy; PPL, pars plana lensectomy; EPC, endophotocoagulation; $\mathrm{IOL}$, intraocular lens; SD, standard deviation

medications. No eyes developed severe hypotony or phthisis bulbi within 1 year after PPV + PPL + EPC + SO tamponade. Twelve of 13 eyes $(92.3 \%)$ had light perception vision 3 months after PPV $+\mathrm{PPL}+\mathrm{EPC}+\mathrm{SO}$ tamponade. Six of ten eyes $(60 \%)$ had improved VA 3 months after SO removal + IOL compared with 3 months after $\mathrm{PPV}+\mathrm{PPL}+\mathrm{EPC}+\mathrm{SO}$ tamponade but this improvement was not statistically significant. Ten of 13 eyes $(76.9 \%)$ had light perception vision 1 year after PPV + PPL + EPC + SO tamponade. The success rates of our procedure were $92.3 \%$ after 3 months and $69.2 \%$ after 1 year.

\section{Discussion}

The surgical results were considered successful because the IOP was well controlled with or without medications and the visual prognosis was good compared with previous reports of vitreous surgery for NVG. ${ }^{22-25}$ In our surgical technique, extensive PRP throughout the pars plana can be applied thanks to PPV + PPL. The major difference between our technique and previously reported vitreous surgery for NVG is that migration of VEGF and inflammatory cytokines from the posterior to the anterior segment is blocked as a result of preservation of the anterior lens capsule and SO tamponade. Rice et ${ }^{2}{ }^{26}$ reported a significant increase in the postoperative incidence of NVG in eyes undergoing combined lensectomy and vitrectomy compared with eyes in which the lens was not removed. Vitreous surgery without preservation of the anterior lens capsule and SO may induce acute production of VEGF and inflammatory cytokines because of retinal damage caused by PRP, which results in an acute immediate worsening of the NVG.

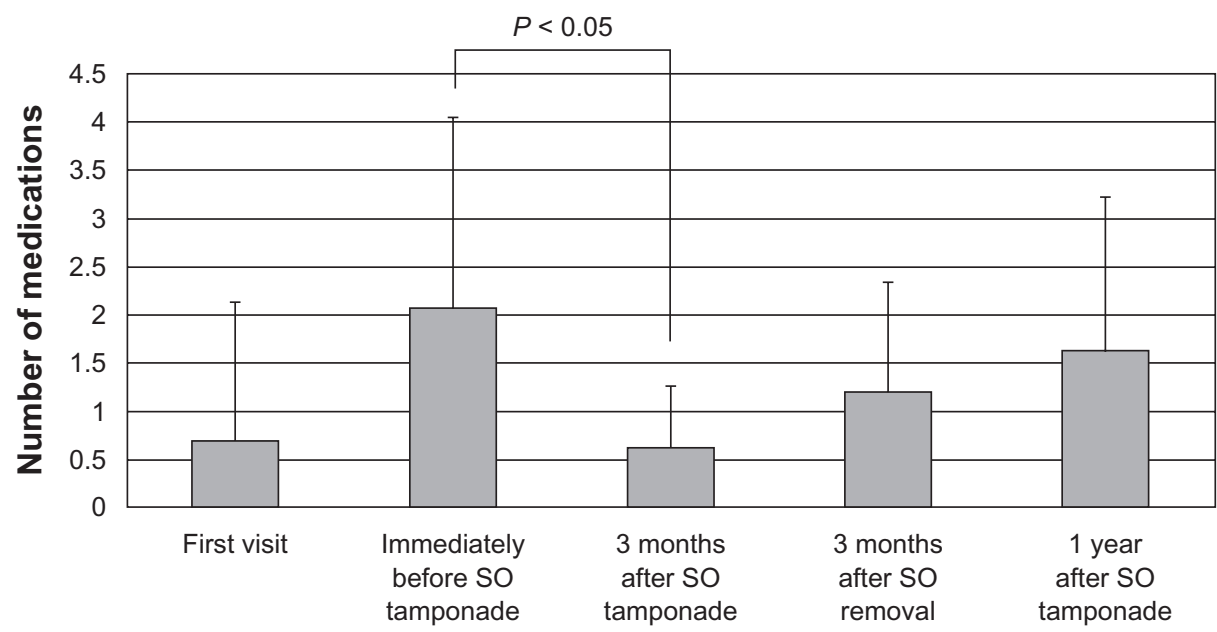

Figure 2 The time course of changes in the numbers of antihypertensive eye drops and oral medications used. At the first visit, immediately before and 3 months after $\mathrm{PPV}+\mathrm{PPL}+\mathrm{EPC}+\mathrm{SO}$ tamponade, 3 months after SO removal + IOL, and I year after PPV + PPL + EPC + SO tamponade, the numbers of medications used (mean \pm SD) were $0.7 \pm 1.4,2.1 \pm 2.0,0.6 \pm 0.7,1.2 \pm 1.2$, and $1.6 \pm 1.6$.

Abbreviations: SO, silicon oil; PPV, pars plana vitrectomy; PPL, pars plana lensectomy; EPC, endophotocoagulation; IOL, intraocular lens; SD, standard deviation 
Bartz-Schmidt et $\mathrm{al}^{22}$ reported on the results of lensectomy including removal of the lens capsule $+\mathrm{PPV}+\mathrm{EPC}+\mathrm{SO}$ tamponade to treat NVG. The differences compared with the current procedure were application of PRP to the ciliary body and the lens capsule was not preserved. Those authors applied PRP to the ciliary body to decrease the aqueous humor yield, but the incidence rate of severe hypotony or phthisis bulbi was high. ${ }^{22}$ We did not observe hypotony and phthisis bulbi in the current cases, because we did not apply EPC to the ciliary body. The current procedure differs from that of Bartz-Schmidt et $\mathrm{al}^{22}$ in that the ciliary body was intact, because the aim of the current procedure was to prevent migration of VEGF and inflammatory cytokines from the posterior to the anterior segment. Therefore, the current procedure might not be as effective for treating advanced angle-closure NVG, although this procedure might be considered to achieve regression of rubeosis. In cases of angle-closure NVG, trabeculectomy or cyclo-cryo/ photocoagulation of the ciliary body should be performed after our procedure.

Trabeculectomy combined with injection of an antiVEGF agent into the vitreous body was performed recently. However, the long-term effect of decreasing the IOP was insubstantial compared with trabeculectomy alone. ${ }^{27,28}$ The anti-VEGF agents caused temporary regression of the iris neovascularization, but the effect dissipated over time.

In conclusion, although NVG remains hard to treat, there may be a chance to preserve the visual function. It is important to prevent the transition from open-angle to angle-closure NVG by performing the procedure at the earliest possible opportunity. PPV + PPL + EPC $+\mathrm{SO}$ tamponade prevented blindness in our case series. We strongly recommend this procedure to treat NVG because it might effectively block VEGF and inflammatory cytokine production with preservation of the anterior lens capsule and SO.

\section{Disclosure}

The authors report no conflicts of interest in this work.

\section{References}

1. Aiello LP, Avery RL, Arrigg PG, et al. Vascular endothelial growth factor in ocular fluid of patients with diabetic retinopathy and other retinal disorders. N Engl J Med. 1994;331(22):1480-1487.

2. Tolentino MJ, Miller JW, Gragoudas ES, Chatzistefanou K, Ferrara N, Adamis AP. Vascular endothelial growth factor is sufficient to produce iris neovascularization and neovascular glaucoma in a nonhuman primate. Arch Ophthalmol. 1996;114(8):964-970.

3. Tripathi RC, Li J, Tripathi BJ, Chalam KV, Adamis AP. Increased level of vascular endothelial growth factor in aqueous humor of patients with neovascular glaucoma. Ophthalmology. 1998;105(2):232-237.
4. Magargal LE, Brown GC, Augsburger JJ, Donoso LA. Efficacy of panretinal photocoagulation in preventing neovascular glaucoma following ischemic central retinal vein obstruction. Ophthalmology. 1982;89(7):780-784.

5. Laatikainen L. Preliminary report on effect of retinal panphotocoagulation on rubeosis iridis and neovascular glaucoma. Br J Ophthalmol. 1977;61(4):278-284.

6. Wand M, Dueker DK, Aiello LM, Grant WM. Effects of panretinal photocoagulation on rubeosis iridis, angle neovascularization, and neovascular glaucoma. Am J Ophthalmol. 1978;86(3): 332-339.

7. Cashwell LF, Marks WP. Panretinal photocoagulation in the management of neovascular glaucoma. South Med J. 1988;81(11):1364-1368.

8. Evans K, Wishart PK, McGalliard JN. Neovascular complications after central retinal vein occlusion. Eye (Lond). 1993;7(Pt 4):520-524.

9. Shazly TA, Latina MA. Neovascular glaucoma: etiology, diagnosis and prognosis. Semin Ophthalmol. 2009;24(2):113-121.

10. Jacobson DR, Murphy RP, Rosenthal AR. The treatment of angle neovascularization with panretinal photocoagulation. Ophthalmology. 1979;86(7):1270-1277.

11. Teich SA, Walsh JB. A grading system for iris neovascularization. Prognostic implications for treatment. Ophthalmology. 1981;88(11): 1102-1106.

12. Weber PA. Neovascular glaucoma. Current management. Surv Ophthalmol. 1981;26(3):149-153.

13. Rehak J. Neovascular glaucoma and intraocular pressure: I. Pathogenesis of increased intraocular pressure and therapy (a review of historical and current therapeutic modalities). Acta Univ Palacki Olomuc Fac Med. 1992;133:71-73.

14. Takihara Y, Inatani M, Fukushima M, Iwao K, Iwao M, Tanihara H. Trabeculectomy with mitomycin $\mathrm{C}$ for neovascular glaucoma: prognostic factors for surgical failure. Am J Ophthalmol. 2009;147(5): 912-918. e1.

15. Kuang TM, Liu CJ, Chou CK, Hsu WM. Clinical experience in the management of neovascular glaucoma. J Chin Med Assoc. 2004;67(3): 131-135.

16. Rehak J. Neovascular glaucoma and intraocular pressure: II. Reduction of intraocular pressure - our 5-year experience. Acta Univ Palacki Oloтис Fac Med. 1992;133:75-77.

17. Borisuth NS, Phillips B, Krupin T. The risk profile of glaucoma filtration surgery. Curr Opin Ophthalmol. 1999;10(2):112-116.

18. Blankenship G, Cortez R, Machemer R. The lens and pars plana vitrectomy for diabetic retinopathy complications. Arch Ophthalmol. 1979;97(7):1263-1267.

19. Schiff WM, Barile GR, Hwang JC, et al. Diabetic vitrectomy: influence of lens status upon anatomic and visual outcomes. Ophthalmology. 2007;114(3):544-550.

20. Kakehashi A. Total en bloc excision: a modified vitrectomy technique for proliferative diabetic retinopathy. Am J Ophthalmol. 2002;134(5): 763-765.

21. Mermoud A, Salmon JF, Alexander P, Straker C, Murray AD. Molteno tube implantation for neovascular glaucoma. Long-term results and factors influencing the outcome. Ophthalmology. 1993;100(6): 897-902.

22. Bartz-Schmidt KU, Thumann G, Psichias A, Krieglstein GK, Heimann K. Pars plana vitrectomy, endolaser coagulation of the retina and the ciliary body combined with silicone oil endotamponade in the treatment of uncontrolled neovascular glaucoma. Graefes Arch Clin Exp Ophthalmol. 1999;237(12):969-975.

23. Sinclair SH, Aaberg TM, Meredith TA. A pars plana filtering procedure combined with lensectomy and vitrectomy for neovascular for neovascular glaucoma. Am J Ophthalmol. 1982;93(2):185-191.

24. Faghihi H, Hajizadeh F, Mohammadi SF, Kadkhoda A, Peyman GA, Riazi-Esfahani M. Pars plana Ahmed valve implant and vitrectomy in the management of neovascular glaucoma. Ophthalmic Surg Lasers Imaging. 2007;38(4):292-300. 
25. Kiuchi Y, Nakae K, Saito Y, Ito S, Ito N. Pars plana vitrectomy and panretinal photocoagulation combined with trabeculectomy for successful treatment of neovascular glaucoma. Graefes Arch Clin Exp Ophthalmol. 2006;244(12):1627-1632.

26. Rice TA, Michels RG, Maguire MG, Rice EF. The effect of lensectomy on the incidence of iris neovascularization and neovascular glaucoma after vitrectomy for diabetic retinopathy. Am J Ophthalmol. 1983;95(1): $1-11$.
27. Chen $\mathrm{CH}$, Lai IC, Wu PC, et al. Adjunctive intravitreal bevacizumabcombined trabeculectomy versus trabeculectomy alone in the treatment of neovascular glaucoma. J Ocul Pharmacol Ther. 2010;26(1): $111-118$.

28. Takihara Y, Inatani M, Kawaji T, et al. Combined intravitreal bevacizumab and trabeculectomy with mitomycin $\mathrm{C}$ versus trabeculectomy with mitomycin C alone for neovascular glaucoma. J Glaucoma. 2011; 20(3):196-201.

\section{Publish your work in this journal}

Clinical Ophthalmology is an international, peer-reviewed journal covering all subspecialties within ophthalmology. Key topics include: Optometry; Visual science; Pharmacology and drug therapy in eye diseases; Basic Sciences; Primary and Secondary eye care; Patient Safety and Quality of Care Improvements. This journal is indexed on

Submit your manuscript here: http://www.dovepress.com/clinical-ophthalmology-journal

\section{Dovepress}

PubMed Central and CAS, and is the official journal of The Society of Clinical Ophthalmology (SCO). The manuscript management system is completely online and includes a very quick and fair peer-review system, which is all easy to use. Visit http://www.dovepress.com/ testimonials.php to read real quotes from published authors. 